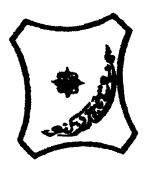

Bayero Journal of Pure and Applied Sciences, 12(1): 57 - 62

ISSN $2006-6996$

\title{
APPLICATION OF ELECTROMAGNETIC AND ELECTRICAL RESISTIVITY METHODS FOR FOUNDATION STUDIES AT AHMADU BELLO UNIVERSITY PHASE II, ZARIA.
}

\author{
Olayinka, L. A., Aremu, B. G., Ahmed, A. L. and Lawal, K. M.
}

Department of Physics, Ahmadu Bello University Zaria, Kaduna State, Nigeria.

Corresponding author: lukmanshina2011@gmail.com; Tel: 07033463561.

\begin{abstract}
Very Low-Frequency Electromagnetic (VLF-EM) and 2D electrical resistivity survey were carried out at the Ahmadu Bello University Phase II in order to investigate the suitability of the soil materials for the foundation of super-structures in the study area. The TerraPlus equipment and ABEM SAS 4000 were used for VLF-EM and resistivity data acquisition respectively. The VLF-EM Data were collected along five (5) profiles at station interval of $10 \mathrm{~m}$ along each profile. The data collected from each of the VLF-EM profile were processed and interpreted with the aid of Karous-Hjelt and Fraser filter software. Electrical resistivity profile was laid on the weak zones revealed by the $2 D$ VLF-EM profiles through the aid of dipole-dipole configuration. The data obtained were processed and interpreted with the aid of Res2Dinv software. Borehole log of the study area was used as additional information which serves as a calibration tool. The $2 D$ imaging profile of VLF-EM highly correlates with resistivity profile. The 2D VLF-EM and resistivity profiles revealed the conductive zone and resistive zones. These zones are suspected to be geological features (dyke, faults and fractures). This geological feature such as fracture zones was filled with an earth's materials which are probably sandy clay and mottled clay, and these materials are highly undesirable for the foundation of building structures due to its characteristics of swelling and contracting during rainy and dry season respectively. Thus, undesirable materials should be excavated and be refilled with suitable materials for the foundation of super-structures and also, geological bodies should be avoided when the foundation of the structures is to be erected.
\end{abstract}

Keyword: VLF-EM, electrical resistivity, foundation of super-structures, geological feature, undesirable materials

\section{INTRODUCTION}

Geophysical investigations have been widely used by the geoscientists and engineers to provide important information about the geology of the subsurface soil, which is a prerequisite for any engineering construction such as building foundation, bridges, road construction and dams. In recent years, the alarming rate at which the engineering structures collapses has brought a greater necessity for which geophysical investigations should be conducted prior to any construction on site. This was as a result of high-quality detailed information usually provided by a geophysical survey on the level of competence of the subsurface soil for engineering foundation.

Ahmadu Bello university phase II is a new site for building of structures (such as academics facilities, students' housing, communal support facilities) that requires a detailed evaluation of the subsurface soil prior to the commencement which are inimical to foundation of any building structures, depth to the bedrock and of any construction on site and the information obtained from this investigation will assist the civil engineers in the setting of foundation structures. There are various methods of a geophysical survey that have been used by many researchers to provide solutions for foundation studies. These include electromagnetic and electrical resistivity survey (Oluwaseun and Oladimeji, 2013), 2D electrical resistivity survey (Arjwech and Everett, 2015), seismic survey (Adewoyin, Joshua, and Akinyemi, 2017), seismic and electrical resistivity survey (Oladunjoye, et al., 2017). According to Alagbe et al., (2013), Electromagnetic using Very Low Frequency (VLF) method provide information about the distribution of fractures which usually revealed themselves as conductive zones within the subsurface earth materials while the 2D electrical resistivity survey usually provide engineers with the information about the nature and trend of geological structures composition of geoelectric layers (Sunmonu et al., 2013). VLF method is an inexpensive method 
Special Conference Edition, November, 2019

that is mostly used for reconnaissance tool in an area of investigation, and it serves as a pointer for follow-up using other techniques such as 2D resistivity survey (Oluwaseun and Oladimeji, 2013).

In this present study, geophysical investigation which involves the use of VLF method and 2D electrical resistivity survey were integrated to investigate the suitability of the subsurface materials for foundation of super-structures at Ahmadu Bello University Phase II. The significance of this research work is to provide information to the engineers prior to construction at the site, about the location of the geological body such as dyke, fracture zones, and fault lines which are hazardous to building foundation, depth to the basement rock, composition and distribution of the subsurface material.

\section{Location and Geology of the Study Area}

The area of study is located within Ahamdu Bello University Phase II, main campus Samaru, Zaria,
Nigeria with latitudes of $11^{\circ} 7^{\prime} 51.5^{\prime \prime} \mathrm{N}$ to $11^{\circ} 8^{\prime}$ $29.9^{\prime \prime} \mathrm{N}$ and longitudes of $7^{\circ} 37^{\prime} 59.10^{\prime \prime} \mathrm{E}$ to $7^{\circ}$ 39' 2.20"E (see Figure 1 and 2a). The area of investigation is situated in the part of NorthWestern Nigeria, and this lies in Nigeria Basement complex rocks of Precambrian age which consists of gneisses, granites and schists. In the area, the predominant rock is biotitic gneisses and it mainly outcrops in stream valley where they are deeply weathered. This rock consists of medium to coarse-grained and foliated rocks which make up a high percentage of the basement complex rocks exposed in the area (Wright and McCurry, 1970). It was also observed by Wright and McCurry, (1970), that the structure of the basement in the area is relatively simple and this was as a result of the uniform regional foliation trends and many joints and fractures were found to have occurred in the area after the Pan-African Orogeny.

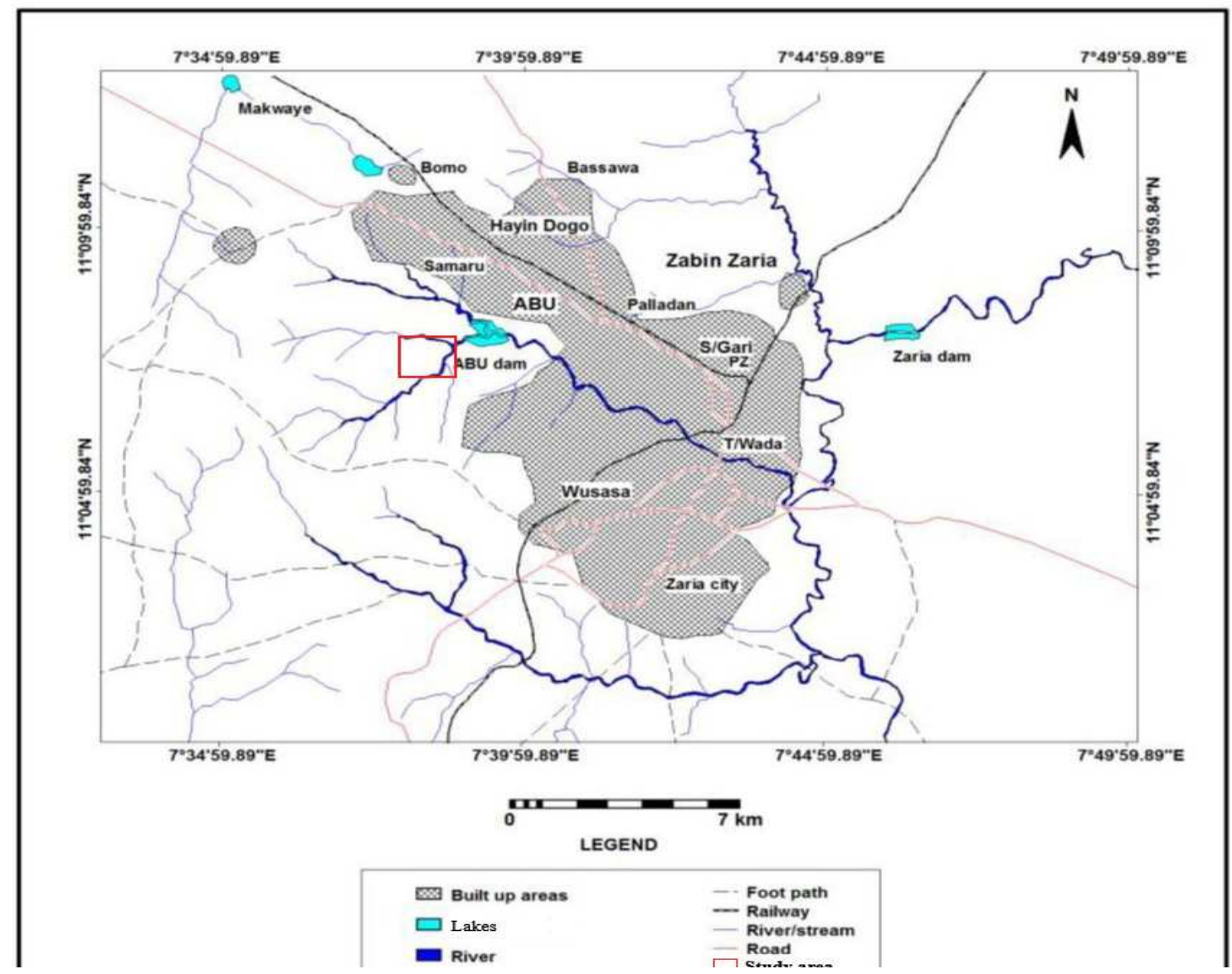

Figure 1: Location of the study area (Modified after Oniye et al., 2014)

The area surveyed is positioned within the South-Western part of the University and it is underlain by porphyritic granite as shown in Figure $2 b$. 


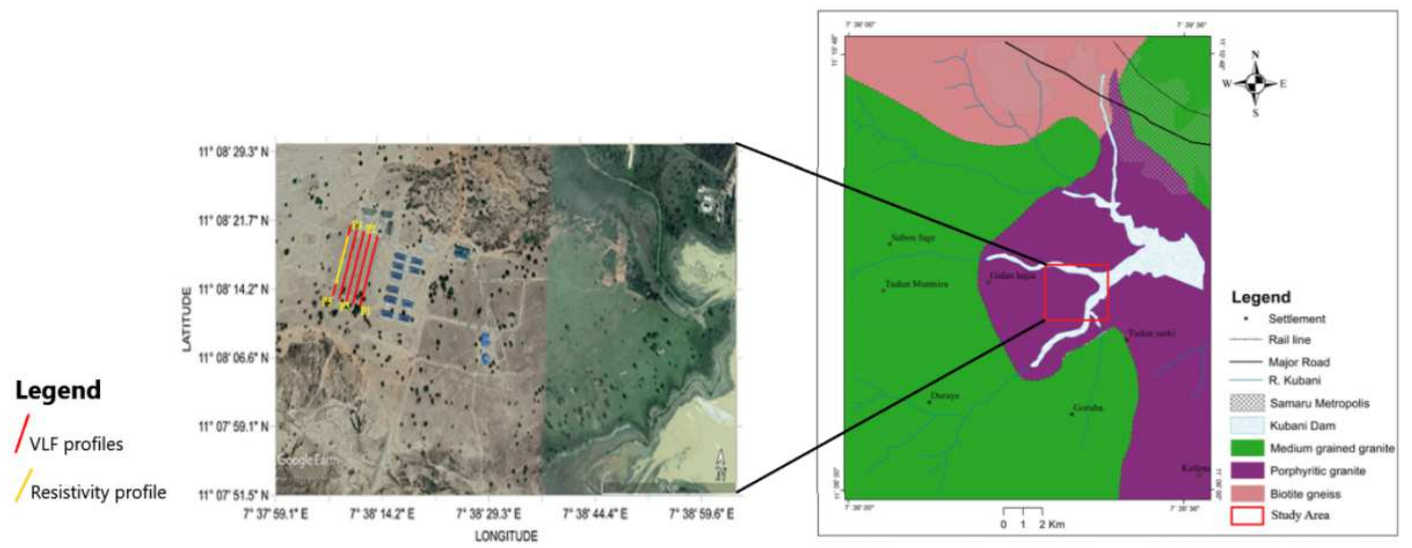

Figure 2: (a) Google earth map showing the direction of the profiles.

(b) Geological map of the study area (Modified after Garba et al., 2014).

\section{MATERIAL AND METHODS}

VLF method is a non-invasive geophysical method that makes use of radio waves and these waves range from $15-30 \mathrm{kHz}$ to locate vertical sheet conductors such as dykes, faults and water-bearing fracture zones which are very sensitive to these radio waves. When a vertical sheet conductor is crossed by the electromagnetic waves, an induced current flow through this conductor and produces a secondary magnetic field $\left(H_{s}\right)$ out-of-phase with the primary magnetic field oriented in any direction (McNeill and Labson, 1991). The transmitted signal is horizontal and linearly polarized in the absence of subsurface electric conductors. However, a resultant polarization of the magnetic field is generated when there is an interference between the primary and secondary magnetic field.

The electromagnetic method (VLF) was used in the study area in order to locate anomalous zones such as fault line, fracture zone and dyke, and this was followed-up by using $2 \mathrm{D}$ electrical resistivity method. The electromagnetic survey method was achieved using Terra-plus VLF equipment, Global Position System (GPS), hammers, pegs, and a measuring tape. The orientation of the profiles (P1-P5) was approximately in the $\mathrm{N}-\mathrm{S}$ direction which was perpendicular to the transmitting station (as shown in Figure $2 \mathrm{a}$ in red lines), with the length of $300 \mathrm{~m}$ long each and inter-profile spacing of $10 \mathrm{~m}$. The VLF Data which consists of the components tilt angle (a) and ellipticity $(\varepsilon)$ were collected along five profiles at station interval of $10 \mathrm{~m}$ along each profile. The data collected from each of the VLF profile were processed and interpreted using Karous-Hjelt and Fraser filter software (KHFFILT), and this was used to generate $2 \mathrm{D}$ subsurface models of the VLF profiles.
The resistivity survey method was used to determine the distribution of the subsurface resistivity based on the response of the flow of current injected into the subsurface with the aid of electrodes. Electric resistivity profile as shown in Figure 2a in yellow line was laid exactly on profile 5 (P5) of the VLF measurement taken from the study area based on the observed weak zones as revealed by the 2D VLF-EM profiles. The resistivity measurement was achieved using ABEM SAS 4000. The data was automatically recorded using dipole-dipole configuration with 41 electrodes distributed along the profile line at $5 \mathrm{~m}$ inter-electrode spacing. The dipole-dipole configuration was used because it is good in mapping horizontal structures such as fault and fracture zone. The data obtained were processed and interpreted using Res2Dinv software (Loke, 2000). Additional information such as borehole log of the study area as shown in Figure 3a was used to correlate with the model obtained from VLF and resistivity imaging and this serves as a calibration tool. This can assist in the interpretation of the VLF and resistivity models obtained from the study area by making it more reliable and also reduces ambiguity in interpretation.

\section{RESULTS AND DISCUSSION}

The interpretation of VLF data was achieved using the Karous-Hjelt and Fraser filter software (KHFFILT). The filtering process was based on Karous and Hjelt (1983) and Fraser (1969) method. Karous and Hjelt (1983) filtering were used to obtain current density pseudo-sections $\left(\mathrm{mA} / \mathrm{cm}^{2}\right)$ and Fraser filter turned the crossing points into peak signals that enhance the conductive structures. 
Special Conference Edition, November, 2019

The two filtering methods show positive and negative anomalies along each of the profile which indicates possible anomalous zone. Figure
$3 \mathrm{~b}$ and 4 show the plot of the Fraser filtered data and Karous-Hjelt models for the five profiles (P1 to P5).
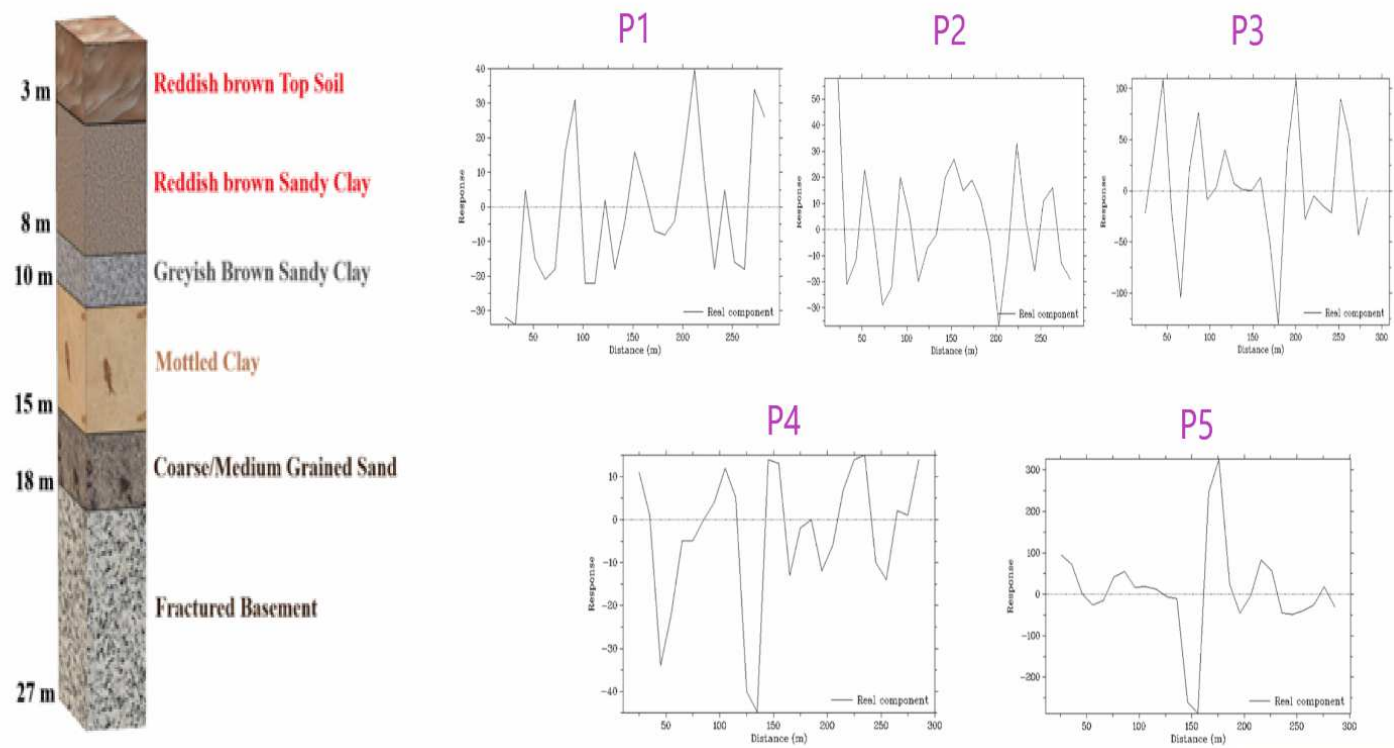

Figure 3: (a) Geological borehole log used for calibration of the models (b) Plot of filtered in-phase data against distance for the five profile (P1 to P5)

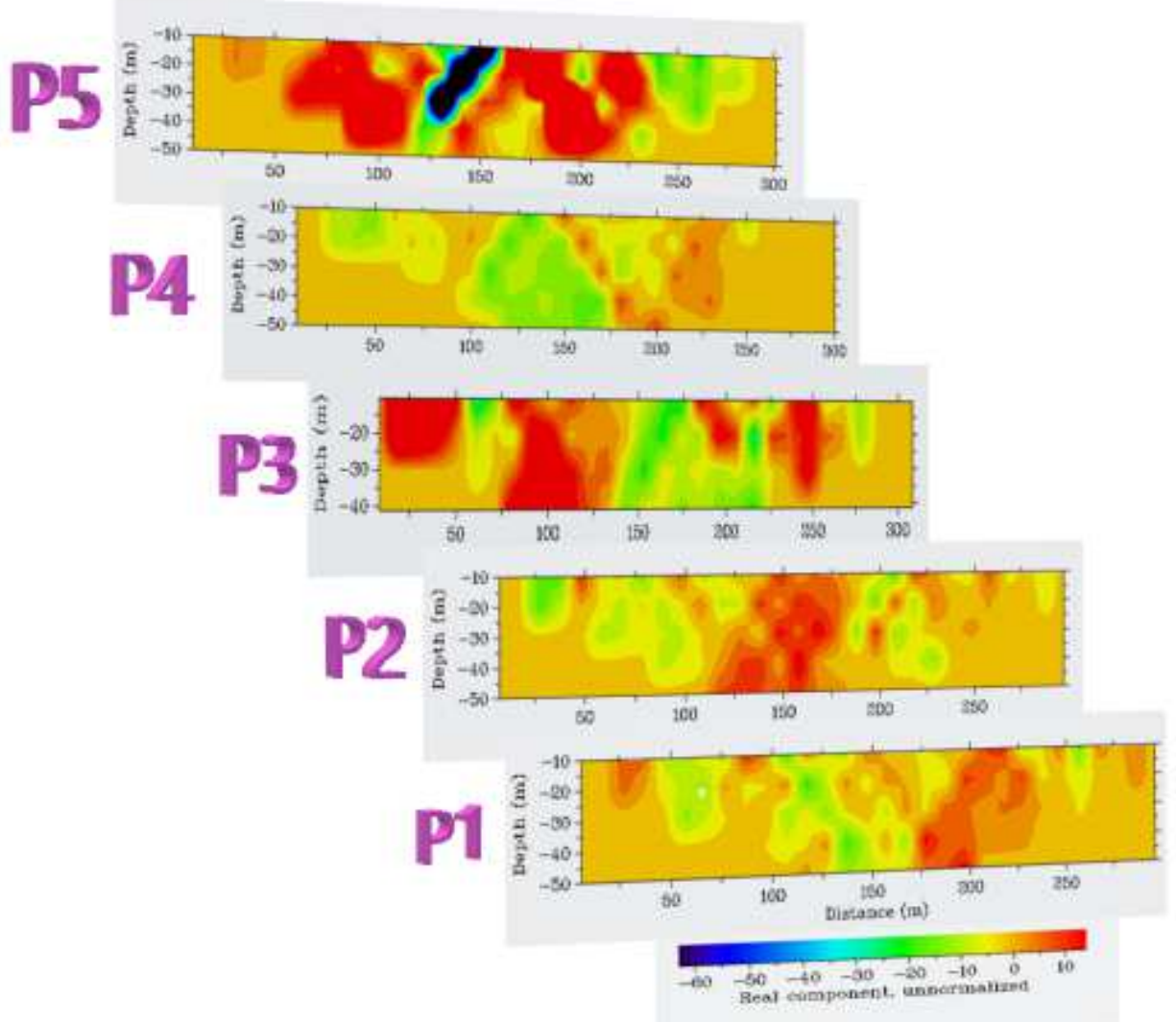

Figure 4: Current density plot of in-phase data against distance for the five profiles 
Special Conference Edition, November, 2019

The VLF 2D models clearly revealed the resistive and conductive nature of the subsurface materials. According to Alagbe et al., (2013) and Sunmonu et al., (2013), the conductive materials are usually indicated themselves as a fracture zone. These conductive zones from the VLF models which might probably be fracture and fault lines zones are filled with sandy clay and mottled clay and these materials dominate the subsurface of the study area while the resistive material is generally low. Figure 4 depicts the 2D subsurface models of the five (5) VLF profiles (P1-P5), with a length of $300 \mathrm{~m}$ $350 \mathrm{~m}$ and depth of range $40 \mathrm{~m}-50 \mathrm{~m}$. The scale of values in Figure 4 represents the current density $\left(\mathrm{mA} / \mathrm{cm}^{2}\right)$, associating positive values $(0$ $\mathrm{mA} / \mathrm{cm}^{2}-15 \mathrm{~mA} / \mathrm{cm}^{2}$ ) to conductive areas.

Along P1, positive anomalies were identified on the VLF imaging profile at a distance of $25 \mathrm{~m}$ $40 \mathrm{~m}$ and $175 \mathrm{~m}-235 \mathrm{~m}$, with the horizontal position of the depths $0-20 \mathrm{~m}$ and $0-50 \mathrm{~m}$ respectively. Conductive zones were revealed on the Fraser filter plot of P2 at the distance of $40-$ $50 \mathrm{~m}, 90-110 \mathrm{~m}, 130 \mathrm{~m}-180 \mathrm{~m}, 210 \mathrm{~m}-230$ $\mathrm{m}$, and $260 \mathrm{~m}-270 \mathrm{~m}$ with a thickness of $20 \mathrm{~m}$, $30 \mathrm{~m}, 50 \mathrm{~m}$, and $40 \mathrm{~m}$ respectively. Pseudosection of the current density of P3 revealed highly conductive features at a lateral distance of $0 m-60 m, 75 m-130 m, 185 m-210 m$, $225 \mathrm{~m}-260 \mathrm{~m}$. These anomalies which might have been caused probably by sandy clay and mottled clay materials are positioned at depths of $0 m-30 m, 0 m-40 m, 0 m-25 m$, and 0 $m-38 m$ respectively. They are mostly oriented in the $\mathrm{N}-\mathrm{S}$ direction. Two conductive zones were spotted along P4. The first positive response, located at a horizontal distance of $150 \mathrm{~m}-200$ $\mathrm{m}$ trending in NW-SE, with a thickness of $40 \mathrm{~m}$ is suspected to have been caused by fracture of the earth material within this region while the second positive response is revealed at a lateral distance $210 \mathrm{~m}-240 \mathrm{~m}$, with a thickness of 45 $\mathrm{m}$ and is oriented in the NE-SW direction.

Profile 5 (P5) of the current density pseudosection revealed highly conductive and resistive near-surface features. The highly conductive features are revealed at the lateral distance of $50 m-115 m, 130 m-150 m, 175 m-230 m$ with an average depth of $50 \mathrm{~m}$ deep. The highly resistive material in $\mathrm{P} 5$, which trend in the NESW direction is located at a lateral distance of $115 \mathrm{~m}-130 \mathrm{~m}$ with a thickness of $30 \mathrm{~m}$. This highly resistive feature was suspected to be dyke and this serves as a point of interest because it usually poses a greater threat to the foundation of a building structure. The suspected feature in P5 was further investigated using the electrical resistivity method. The resulting 2D electrical resistivity imaging of P5 (VLF profile 5) is shown in Figure 5.

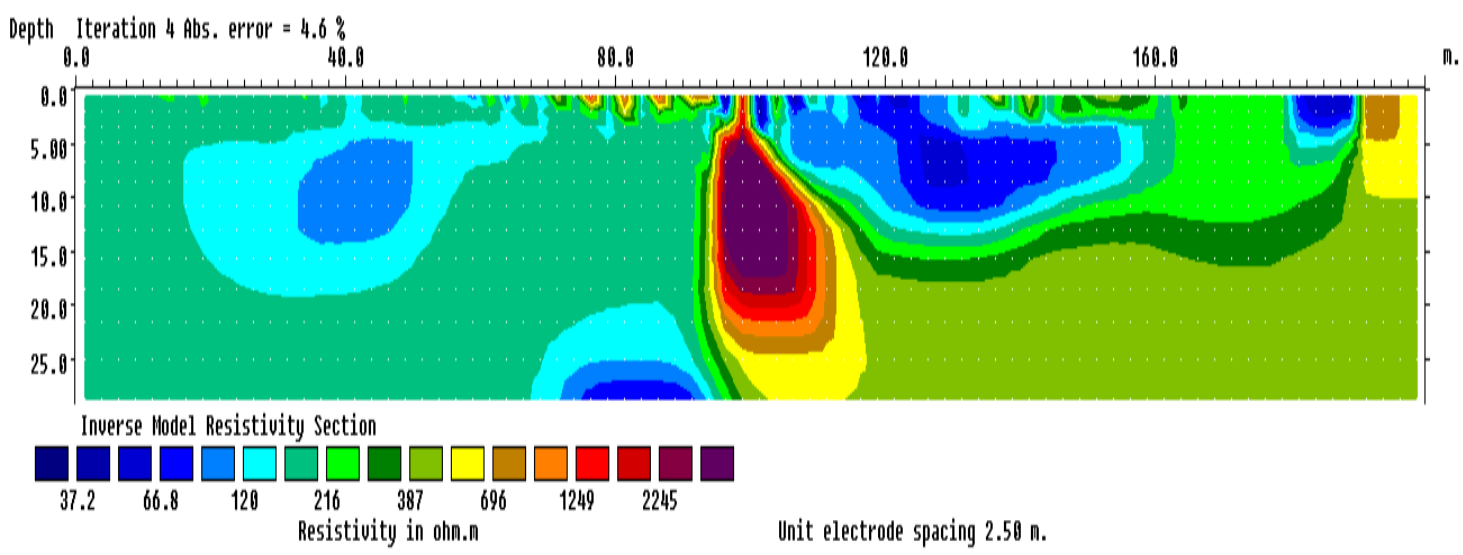

Figure 5: 2D resistivity imaging of P5

The inverted section of two-dimensional resistivity tomogram revealed three main zones (Moderate-highly resistive and conductive zones). The moderate resistive zone of value $387 \Omega \mathrm{m}$ to $1000 \Omega \mathrm{m}$ is revealed at a lateral distance of $110 \mathrm{~m}-200 \mathrm{~m}$ and at the depth of $10 \mathrm{~m}$, which might probably consist of coarse/medium-grained sand material. The highly resistive zone is clearly revealed at a lateral distance of $100 \mathrm{~m}$, with a resistivity value of range $1249 \Omega \mathrm{m}$ to $2245 \Omega \mathrm{m}$ and thickness of almost $30 \mathrm{~m}$ deep in the centre part of the profile. The suspected geological body in this zone is dyke, which also revealed itself as a high resistive zone in VLF profile P5. 
Special Conference Edition, November, 2019

The conductive zone which nearly dominates the entire profile consists of probably sandy clay and mottled clay with a resistivity value between the range of $55.9 \Omega \mathrm{m}$ to $216 \Omega \mathrm{m}$. This result obtained for the 2D electrical resistivity imaging, highly correlated with the pseudo-section of the current density of VLF profile P5.

\section{CONCLUSION}

The electromagnetic and electrical resistivity method has been conducted at Ahmadu Bello University Phase II to investigate the suitability of the subsurface materials for foundation studies. The electromagnetic method (VLF) was carried out in the study area in order to locate anomalous zones such as fault line, fracture zone and dyke, and this was followed-up by using $2 \mathrm{D}$ electrical resistivity method to further complement the anomalous structures observed from VLF survey. The 2D pseudo-section of the VLF and electrical resistivity profiles has revealed geological bodies which are inimical to building the foundation. This geological body such as fracture zones are filled with an earth's materials which are probably sandy clay and mottled clay,

\section{REFERENCES}

Adewoyin, O. O., Joshua, E. O., and Akinyemi, M. L. (2017). Application of geophysical and geotechnical methods to determine the geotechnical characteristics of reclaimed land. Adapted from extended abstract prepared in conjunction with an oral presentation given at AAPG/SPE 2016 International Conference \& Exhibition, Barcelona, Spain. April 3-6, 2016.

Alagbe, O.A; Sunmonu, L.A and Adabanija, M A (2013): Fracture distribution within Bowen University Permanent site and its hydrogeologic implication. Research Journal of Physical Sciences $1(3), 1-5$.

Arjwech, R., and Everett M. E. (2015). Application of $2 D$ electrical resistivity tomography to engineering projects: Three case studies. Songklanakarin J. Sci. Technol., 37 (6), pp. 675681, 2015.

Fraser, D. C. (1969). Contouring of VLF-EM data. Geophysics, Vol. 34, pp. 958-967.

Garba, M. L., Yusuf Y. O., Arabi, A. S., Musa, S. K. and Schoeneich, K. (2014). An Update on the quality of water in Samaru Stream, Zaria, Nigeria. Zaria Geographer, vol. 21, No. 1.

Karous M. R., and Hjelt S.E. (1983). Linear filtering of VLF dip-angle measurements. Geophysical Prospecting, Vol 31, 782-794.

Loke, M. H. (2000). Electrical imaging surveys for environmental and engineering studies; A practical guide to 2-D and 3-D surveys. Electronic version available from http:// www.terraplus.com. and these materials are highly undesirable for the foundation of building structures due to its characteristics of swelling and contracting during rainy and dry season respectively. Resistive material such as coarse/medium-grained sand was also encountered along with the VLF and resistivity profiles. This material is the most suitable material, and can also support massive engineering structure in the study area. Therefore, geological bodies such as fault and fracture zones should be avoided when the foundation of the structures is to be erected. Moreover, Undesirable materials should be excavated and be refilled with suitable materials for the foundation of super-structures at the Ahmadu Bello University Phase II.

\section{ACKNOWLEDGEMENT}

The authors wish to thank Prof. A. Giwa, Dr Raimi Jimoh, Mr Kabir Momoh, Mr Marcus Gideon, Abdulkadir Shehu Tijjani, and Department of Physics, Ahmadu Bello University Nigeria, for their support and guidance throughout this research.

McNeill, J. D., and Labson, V. F. (1991). Geological Mapping Using VLF Radio Fields. Electromagnetic Methods in Applied Geophysics (pp. 521-587).

Oladunjoye, M. A., Salami, A. J., Aizebeokhai, A. P., Sanuade, O. A., and Kaka, S. I. (2017). Preliminary geotechnical characterization of a site in southwest Nigeria using integrated electrical and seismic methods. Journal geological society of India, Vol. 89, pp. 209-215.

Oluwaseun, S. O., and Oladimeji, L. A. (2013). Integrated geophysical studies for postfoundational investigation in part of Afe Babalola University, Ado-Ekiti, Nigeria. Journal of Emerging Trends in Engineering and Applied Sciences., 4(4): 654-660.

Oniye, S. J., Tanimu, Y., Chia, A. M., and Yusuf, D. (2014). Influence of clarias gariepinus (Teugels) cage cultures on water quality, phytoplankton and periphyton composition: A case study Ahamdu Bello University reservoir, Nigeria. Tropical Freshwater Biology, 23(2014), pp. 2137.

Sunmonu, L. A., Alagbe, O. A., Mabunmi, S. A., Adeniji, A. A., and Olasunkanmi, N. K. (2013). Geophysical investigation into the cause(s) of structural failure within Bacosa and faculty of science buildings, Bowen university temporary site, Iwo. Advanced in physics theories and applications, Vol 25., pp.1-18.

Wright, J. B., and McCurry, P. (1970). The geology of Nigeria Sheet 102 SW, Zaria and its regions. Department of Geography, Occasional paper, No. 4, Ahmadu Bello University, Zaria. 